Investigaciones Fenomenológicas, n. 11, 2014, 57-79.

e-ISSN: $1885-1088$

\title{
LA Fenomenología dialÉctica de EduARdo Nicol*
}

\section{Eduardo Nicol's Dialectical Phenomenology}

Resumen: El presente trabajo tiene la finalidad de mostrar la fenomenología dialéctica de Eduardo Nicol. Para ello parto de lo que considera Nicol el origen de la crisis de la metafísica. Identificado el origen de tal crisis, expondré los tipos de relación del conocimiento que existen en relación a lo que Nicol llama "ontología de la verdad". En esta exposición, mostraré el sentido que adquiere para Nicol el carácter apodíctico de la experiencia y la relación existente entre método y ontología. Estas dos ideas nos revelarán la importancia que tiene el "otro" en el desarrollo fenomenológico nicoliano así como el sentido de la historicidad.

Como consecuencia, la fenomenología dialéctica se presenta como un método que pretende dar solución a la crisis de la metafísica continuando la tradición fenomenológica iniciada por Husserl a través de una revisión de la misma.

Palabras clave: Fenomenología | Dialéctica | Historicidad

\author{
Francisco Javier Cortés Sánchez \\ Universidad de Salamanca, España \\ francortes@usal.es
}

\begin{abstract}
This research is intended to show the phenomenological method of Eduardo Nicol. To do this I start from the consideration of Nicol regarding the origin of the crisis of metaphysics. Identified the origin of this crisis, I will explain the relationship types of knowledge that exist in relation to what Nicol called "ontology of truth." In this presentation, I will show the meaning that for Nicol has the apodictic character of experience and the relationship between method and ontology. These two ideas will reveal the importance of the "other" in the phenomenological development and sense of historicity.

As a result, dialectical phenomenology is presented as a method that aims to answer the crisis of metaphysics continuing the tradition begun by Husserl through a review of it.
\end{abstract}

Key Words: Phenomenology | Dialectic | Historicity

El título del presente trabajo puede presentar algo de confusión debido a los diferentes sentidos que han adquirido en la historia de la filosofía los conceptos "fenomenología" y "dialéctica". Quizás pueda causar más confusión el

\footnotetext{
* Ponencia presentada en el X Congreso Internacional de la Sociedad Española de Fenomenología. "Fenomenología, experiencia y razón. Centenario de Ideas I", Barcelona, 27-29 Noviembre, 2013.
} 
segundo que el primero dado los usos que se han manejado del término "dialéctica" en la tradición hegeliana y marxiana. Por ello, para no caer en dificultades, lo primero de todo decir que el sentido del término dialéctica en Nicol no tiene un sentido hegeliano, sino que su sentido tiene que ver con el carácter dialógico del pensamiento. Es decir, que una de las características del pensamiento, según Nicol, es el diálogo. En este sentido el término "dialéctica" en Nicol está más cercano al sentido socrático-platónico.

Por otro lado, el concepto "fenomenología" no debería producir tales confusiones como el término anterior, pero no escapa a las cuestiones como: ¿Qué se puede entender por fenomenología? ¿Qué es la fenomenología?

Después de un siglo de la publicación de Ideas I estas preguntas siguen teniendo actualidad ya que las investigaciones fenomenológicas han aumentado, e incluso dentro de la propia fenomenología, los enfoques y modos de entender este proyecto de ciencia estricta se han diversificado.

Si bien podemos considerar a Husserl el padre de la fenomenología, el uso de dicho término puede rastrearse en la historia de la filosofía y retrotraerse a sus primeros usos, los cuales, preceden a la obra del mencionado filósofo. Pero en la actualidad, cuando se habla de fenomenología no se piensa, por ejemplo, en La fenomenología del espíritu de Hegel, sino que se identifica con el proyecto filosófico de Edmund Husserl junto con los proyectos que se inspiraron en su obra. Es así como dentro de la fenomenología entran proyectos filosóficos como los de Max Scheler, Heidegger, Sartre, Merleau-Ponty, Paul Ricoeur... Proyectos que amplían la diversidad de la fenomenología pero que también es vista para muchos otros como una distorsión del proyecto originario.

El propio Husserl sintió que el proyecto de su discípulo Heidegger se alejaba de la intención original de la fenomenología y, en este sentido, las preguntas anteriormente mencionadas recorren la historia de la fenomenología, la cual llega hasta nuestra actualidad. En medio de este recorrido por la historia de la fenomenología se encuentra el filósofo catalán Eduardo Nicol ${ }^{1}$.

\footnotetext{
${ }^{1}$ Eduardo Nicol nació en Barcelona en 1907. En esa ciudad es donde prácticamente desarrolló toda su formación hasta 1939, que por motivos bélicos conocidos, conoció el exilio. En México estableció su residencia y lugar de trabajo (Facultad de Filosofía y Letras de la UNAM). Viajó por América y Europa realidando cursos y conferencias. Un dato, quizás relevante para esta ocasión, ya que nos encontramos en el X Congreso Internacional de la Sociedad Española de Fenomenología, es que fue miembro de la International Phenomenological Socitety y consejero de la revista Philosophy and Phenomenological Research de EEUU desde 1944. En 1990 muere en la ciudad de México. Sobre datos biográficos acerca de Eduardo Nicol puede consultarse: R. de Nicol, Alicia, "Eduardo Nicol. La vocación cumplida". Eduardo Nicol. La filosofía como razón simbólica, Revista Anthropos, Extra 3 (1998), 46-55. También puede con-
} 
La intención de este trabajo no pretende mostrar las coincidencias y disidencias entre Husserl y Nicol, tampoco es pretensión posicionarse en la defensa de alguno de los proyectos filosóficos mencionados. La intención simple y llana es mostrar el sentido que adquiere para Nicol la fenomenología. Es así que, como inevitable consecuencia, se presenten las diferencias con la fenomenología de Edmund Husserl, pero las presentaciones de tales diferencias son presentadas desde las argumentaciones propias de Eduardo Nicol. La pregunta clara es la siguiente: si la filosofía de Eduardo Nicol es considerada como fenomenología dialéctica, ¿en qué sentido podemos entender que es fenomenológica?

El propósito de este trabajo es, por tanto, mostrar la fenomenología dialéctica de Eduardo Nicol. Para ello considero que hay que tener presente cómo experimenta Nicol la situación del siglo XX en relación al saber filosófico y por ello voy a partir de lo que considera Nicol el origen de la crisis de la metafísica. Identificado el origen de tal crisis, expondré los tipos de relación del conocimiento que considera Nicol que existen. En esta exposición, mostraré el sentido que adquiere para Nicol el carácter apodíctico de la experiencia y la relación existente entre método y ontología. Estas dos ideas nos revelarán la importancia que tiene el "otro" en el desarrollo fenomenológico nicoliano así como el sentido de la historicidad.

Para Nicol la crisis que está atravesando la filosofía en el siglo XX es una crisis de principios, pero esta crisis de principios no solo afecta a la filosofía sino que también afecta directamente a las ciencias, en concreto él nos habla de la crisis de la ciencia física y metafísica. Estas son sus palabras:

Decimos, pues, que la ciencia se encuentra ahora en una situación crítica, y que la crisis, en tanto que es principal, atañe a todas las ciencias. Sin embargo, presenta caracteres más llamativos en la física y en la metafísica. La crisis de la metafísica tiene un aspecto negativo, y consiste en la incapacidad que ella ha mostrado en el siglo XX de revelar la unidad fundamental de la ciencia y de precisar, en los términos que correspondan al nivel que las ciencias positivas han alcanzado, cuáles son las condiciones universales y necesarias del conocimiento en general.

La ausencia de un cuerpo de doctrina bien organizado sobre esta cuestión principal se ha combinado, en la física, con las circunstancias internas que en esta ciencia

sultarse: Horneffer , Ricardo, "Eduardo Nicol (1907-1990)" en E. Dussel; E. Mendieta; C. Bohórquerz (editores), El pensamiento filosófico latinoamericano, del Caribe y "latino" (1300-2000): historia, corrientes, temas y filósofos, México, Siglo XXI, 2009, 837-838. 
promovieron su crisis particular [...] Pues, en efecto, esta crisis de la física tiene más bien caracteres positivos: no presenta como síntoma una paralización, sino más bien un crecimiento desbordante, excesivamente acelerado. Los descubrimientos se adelantan demasiado a los "esquemas teóricos" en que hubo de fundarse la investigación que permitió lograrlos". ${ }^{2}$

El reto de la metafísica del cual habla Nicol en el texto citado consiste en revelar la unidad fundamental de la ciencia así como mostrar las condiciones universales y necesarias del conocimiento. A la vez, otro de los retos consiste en entender, dentro de esa unidad fundamental, el crecimiento desbordante de la ciencia. El centro de donde emanan todas las direcciones de la crisis lo identifica Nicol con la historicidad. Han sido las corrientes historicistas aquellas que nos han hecho conscientes de la historicidad de los saberes sin embargo, no es el hecho de que sean históricos los saberes lo que causa la crisis, sino que los mismos hombres de ciencia no pueden dar cuenta de la fluctuación de sus saberes que parecen actuar bajo distintos principios en los que se apoyaba la ciencia clásica. El conflicto surge cuando se presenta la aparente incompatibilidad entre el hecho de la historicidad de la ciencia y el valor intemporal que se le asignaban a las leyes. Es cuestión, por tanto, de la metafísica pensar el fundamento legítimo, ya que son problemas metafísicos (ontológicos, metodológicos y epistemológicos). La cuestión es la aclaración de las condiciones efectivas de posibilidad y legitimidad de manera unitaria y común para todas las ciencias. Y esta tarea es metafísica, es decir, de la ciencia primera, la ciencia de los principios, es en éste sentido tal y como lo entiende Nicol.

En una situación similar se encuentra Husserl cuando escribe contra el psicologismo, el naturalismo y el historicismo. El intento por encontrar un fundamento radical (en el sentido de raíz) le llevará a formular su fenomenología trascendental. Sin embargo, Nicol encuentra varias deficiencias en la fenomenología de Husserl y la primera de ellas es la reducción que hace de los fenómenos en virtud de salvar las esencias. Para Nicol, la fenomenología trascendental se basa sólo en dos de las cuatro relaciones que tiene el conocimiento y, en base a esas dos relaciones elabora un fundamento de derecho, pero no de hecho, perdiendo así el verdadero sentido de la fenomenología, que es ir a las cosas mismas.

\footnotetext{
${ }^{2}$ Nicol, Eduardo, Los principios de la ciencia, México, Fondo de Cultura Económica, 1974, p. 13.
} 
Las dos relaciones del conocimiento a las cuales atiende la fenomenología trascendental es a la relación epistemológica y a la relación lógica. Nicol dice que son, por tradición, aquellas relaciones a las cuales la filosofía siempre ha atendido prescindiendo de la relación histórica y dialógica.

Pues bien, a continuación voy a exponer las cuatro relaciones del conocimiento de las cuales se pronuncia Nicol y así mostrar su idea de la fenomenología dialéctica. Estas cuatro relaciones son: epistemológica, lógica, histórica y dialógica ${ }^{3}$.

La relación primaria que se establece en torno al conocimiento es la relación epistemológica. Es decir, la relación que se establece entre el sujeto de conocimiento y los objetos en general. Antes de que el pensamiento se convierta en conocimiento ya se establece una relación entre el sujeto y los objetos.

La filosofía, en sus orígenes, es la que cambia la forma de relacionarse con los objetos. La distinción entre doxa y episteme tiene que ver con el esclarecimiento de esta relación. La intención es responder a la cuestión del cómo y el por qué. El advenimiento de la filosofía trajo consigo un giro. La filosofía cambia el punto de apoyo y, en lugar de ser la tradición quien dé cuenta a la respuesta de dichas preguntas, es el filósofo quien pone el acento en los objetos. No obstante, la presencia de los objetos por sí misma no dice nada. Es en este sentido cuando se toma conciencia de que el conocimiento no es algo pasivo, sino que es activo. La percepción de los objetos la tienen todos los hombres por igual, tanto aquel que responde al rayo como obra de los dioses como aquel que intenta dar cuenta de aquel suceso desde los objetos mismos. La cuestión del conocimiento, por tanto, no consiste en quedarse en la mera percepción sino en dar cuenta de la relación que existe entre los objetos. Por ello, considera Nicol, que la filosofía lo que hace es introducir la causa dentro del orden de los objetos. La introducción de la causa dentro de las explicaciones epistemológicas permite apelar a algo externo, ese algo externo es un nexo existente entre los objetos, una fuerza que los une, que los conexa ${ }^{4}$.

\footnotetext{
${ }^{3}$ Para una aproximación a las cuatro relaciones del conocimiento puede consultarse: Nicol, Eduardo, LoS principios de la ciencia, México, Fondo de Cultura Económica, 1974, segundo capítulo.

${ }^{4}$ No obstante, esta relación epistemológica entendida como la relación entre sujeto y objeto no podrá entenderse en el sentido tradicional de representación, pero la aclaración de este punto se comprenderá más adelante con la relación dialógica. La relación dialógica, junto con la relación histórica, suponen un cambio en la relación epistemológica ya que, según Nicol, el peso no recae en la representación sino en la expresión.
} 
El problema que surge de esta nueva relación es la pérdida de la fuerza vinculatoria que tenía el mito con la comunidad. La filosofía, así, se ve obligada a establecer un nuevo vínculo para la comunidad del pensamiento, y esa nueva institución será la razón lógica.

En este sentido, la tarea de la filosofía consiste en una paideia según la cual el sujeto ha de subordinarse al objeto. La objetividad, por tanto, es tarea del pensamiento y no de la percepción, ya que la percepción es común a todo pensamiento, tanto de la doxa como de la episteme. El problema radica en el tipo de relación que se establece.

Esta relación que Nicol llama "objetividad" y que consiste en la subordinación del sujeto ante el objeto, entra en crisis con la modernidad en la cual los papeles quedan invertidos. En esta etapa se establece una primacía del sujeto cognoscente frente al objeto conocido y cuya máxima expresión llega a formularse a través del problema del mundo (en sentido epistemológico y ontológico). Es así como el mundo se convierte en problemático cuando en realidad, nos dice Nicol, los problemáticos somos nosotros, los hombres.

La búsqueda de la evidencia a través del método es la expresión máxima de este tipo de idealismos que convierten la cuestión del fundamento en una cuestión de derecho, en lugar de repensar desde la posibilidad del ente que se pregunta por el ser (cuestión de hecho). Es así como tanto la filosofía de Descartes como la de Husserl convierten el mundo en problemático. La tarea tanto de la duda metódica como de la fenomenología trascendental es encontrar la evidencia para luego levantar el orden de la explicación segura. Este tipo de filosofías establecen un dualismo que divide el conocimiento en doxa y episteme. Es aquí donde Nicol encuentra el error fundamental, considerar a la doxa como un tipo de conocimiento. El propio Nicol lo expresa así:

El equívoco es éste, y en él incurre Husserl lo mismo que Descartes: se cree implícitamente que sólo el conocimiento científico puede librar el ser; la ciencia se instituye, según esto, aparte del conocimiento precientífico e incluso se contrapone a él [...] esa confusión no hace sino reiterar los términos de la antigua distinción platónica y aristotélica entre doxa y episteme ${ }^{\prime \prime}{ }^{5}$

\footnotetext{
${ }^{5} \mathrm{Nicol}$, Eduardo, Metafísica de la expresión, México, Fondo de Cultura Económica, 1957, p. 176.
} 
Si pensamos desde las filosofías de Descartes y de Husserl, podemos observar cómo el método de éstas hace posible el conocimiento verdadero. Es el método el que descubre la evidencia y sólo desde la evidencia se puede llegar metodológicamente a la verdad. Sin embargo, Nicol nos dice que tanto el método como el conocimiento son posteriores al fundamento, porque toda construcción presupone un cimiento y la ciencia es construcción. Es en este sentido cuando vemos que no es el método el que permite encontrar las evidencias primarias y apodícticas sino al revés, desde las evidencias compartidas se levanta todo tipo de pensamientos, donde entran tanto la doxa como la episteme.

Nicol, ante esto, hace una reivindicación del fenómeno, del ser. Es por este motivo por el cual Nicol reclama a la filosofía como fenomenología, ésta la entiende del siguiente modo: "La fenomenología es conocimiento inmediato del Ser del ente. La ciencia ha de salvarse, no por su formalidad (trascendental o lógica), sino como un saber objetivo de realidades. Ser es realidad: el Ser es fenómeno" ${ }^{\prime 6}$.

Él quiere seguir el imperativo fenomenológico de ir a las cosas mismas y este afán por ir a las cosas mismas le hace ver con sospecha la duda del mundo y su puesta entre paréntesis. La búsqueda de la evidencia es un falso problema, nos dice, ya que la evidencia es punto de partida tanto para la doxa como para la episteme. Sin embargo, para Husserl, la evidencia es entendida desde la episteme y, en este sentido, entran tanto el acto de juzgar como los propios juicios lógicos ${ }^{7}$, lo cual le conduce al siguiente principio metodológico: "con vistas de obtener una esfera del ser absolutamente indubitable [...] el intento de duda universal sólo debe servirnos como instrumento metódico para poner de relieve ciertos puntos que son susceptibles de ser sacados a la luz con evidencia mediante este intento, en cuanto entrañados en su esencia"8 ${ }^{8}$. Y este principio metodológico de Husserl queda definido de la siguiente forma: "por medio del método del colocar entre paréntesis [...] Ponemos fuera de juego la tesis general inherente a la esencia de la actitud natural' ${ }^{\prime 9}$. Esto es la èpokhé feno-

\footnotetext{
${ }^{6}$ Nicol, Eduardo, Crítica de la razón simbólica, México, Fondo de Cultura Económica, 1982 p. 170.

${ }^{7}$ Cf. Husserl, Edmund, Ideas relativas a una fenomenología pura y una filosofía fenomenológica, traduc.

J. Gaos, Madrid, Fondo de Cultura Económica, 1985, § 136.

${ }^{8}$ Husserl, Edmund, o.c., p. 70.

${ }^{9}$ Iíbd., p. 73
} 
menológica, la cual conduce a lo siguiente: "El mundo entero, puesto en la actitud natural [...] no vale para nosotros ahora nada"10.

Pero, para Nicol, lo que diferencia a la opinión del conocimiento no es su carácter evidente, ya que ambos parten de la misma evidencia. La evidencia, por tanto, nunca es problemática ya que esto sería un contrasentido. Por ello dice Nicol que: "La más primitiva y consabida de todas las verdades: Hay $S r^{\prime 11}$. La evidencia apodíctica es que hay ser, por tanto, la opinión como el conocimiento parten del ser, que se presenta como fenómeno. La diferencia entre doxa y episteme, en este sentido, no se encuentra en la evidencia. La diferencia radica en que mientras la opinión puede ser arbitraria e infundada, la episteme es siempre rigurosa y sistemática.

No obstante, la relación epistemológica del conocimiento, que consiste en esa relación que se establece entre el sujeto de conocimiento y los objetos, no se vale por sí misma. De la exigencia de la subordinación del sujeto al objeto surge la idea de verdad como adecuación, pero esta idea de verdad no es autosuficiente. Es decir, no basta ponerse de acuerdo con la realidad sino que además es necesario un discurrir acerca de esas evidencias. Para este discurrir se necesita una conducta regular y uniforme del discurso. Es así como se instituye la lógica. Porque no es suficiente la relación del objeto con el sujeto sino también la relación del pensamiento consigo mismo. Es así como entramos en la segunda relación del conocimiento, la relación lógica.

El pensamiento verdadero queda definido por una doble relación y esta doble relación es la epistemológica y la lógica que consiste en la adecuación con lo real y la adecuación consigo mismo. Nicol al respecto quiere hacer una aclaración y es que aunque la lógica se convierta en una parte esencial para el pensamiento verdadero, esto no hace que el resto del pensamiento sea alógico. Es más, todo pensamiento es lógico, es logos. Nicol lleva a cabo una distinción entre la llamada lógica natural y lógica normativa. La lógica natural es la gramática. La gramática es la lógica primaria del lenguaje. La lógica normativa es la que se ha llamado ciencia, pero no se trata ni de una invención, ni de un descubrimiento de una nueva dimensión del logos, sino que simplemente es

\footnotetext{
${ }^{10}$ Ibíd., p. 74

${ }^{11}$ Nicol, Eduardo, Los principios de la ciencia, México, Fondo de Cultura Económica, 1965, p. 302. Cf. González Valenzuela, Juliana, "El ser que habla del ser (Metafísica y Ética en Eduardo Nicol)". Eduardo Nicol. La filosofía como razón simbólica, Revista Anthropos, Extra 3 (1998), 58
} 
una técnica convertida en sistema regulador del pensamiento que, naturalmente, ya existe en el logos. "Sólo alcanzan la univocidad deseada las ciencias formales. Por esto ellas son, literalmente, incomprensibles: los términos pudieron definirse de una vez por todas porque carecen de significado real. Lo que nada significa no expresa nada. Las demás ciencias son expresivas porque son significativas" ${ }^{12}$.

Por ello Nicol quiere dejar claro que la relación primaria del conocimiento es la epistemológica, que es aquella relación cognoscitiva. El logos como técnica depurada, es decir, la lógica, es una especie de instrumento que depura, normaliza y unifica la función epistemológica. Por ello la lógica nunca puede resolver, por sí misma, ningún problema del conocimiento. La lógica (que es el aspecto formal del conocimiento y cuyo valor reside en la coherencia interna) siempre ha de estar al servicio de la epistemología (que es el aspecto material y cuyo valor reside en la referencia a la cosa).

La independencia que han logrado las ciencias llamadas formales ha hecho que se llegue a creer en el formalismo según el cual se da una primacía de la lógica normativa frente a la epistemología. Pero al igual que sucede con la relación primaria del conocimiento donde el sujeto ha de subordinarse a la cosa, la lógica ha de subordinarse a la epistemología. En la historia, dice Nicol, nos encontramos con diferentes sistemas simbólicos que tienen su propia lógica, ejemplo de ello son las matemáticas no euclideanas. Por otro lado, el principio que rige a la lógica normativa que más conocemos es el principio de no contradicción, pero también existe la lógica no parmenideana, es decir, la lógica dialéctica. Lo que quiere decir Nicol es que toda utilidad de cualquier lógica se funda siempre en lo ontológico. En este sentido, la lógica parmenideana o parmenidea es una lógica intemporal, que por su carácter le es imposible pensar el cambio. Pero el hecho de la historicidad nos exige pensar el tiempo y esto sólo es posible a través de una lógica que conciba el cambio, esta lógica es la lógica dialéctica. Es así como entramos en la tercera relación del conocimiento de la que habla Nicol, la relación histórica.

El problema que plantea la historicidad es el siguiente: si la verdad se alcanza a través de la adecuación material y formal ¿cómo puede ésta ser históri-

\footnotetext{
12 Nicol, Eduardo, Crítica de la razón simbólica, México, Fondo de Cultura Económica, 1982 p. 66.
} 
ca? Es decir, la verdad no puede ser temporal e intemporal al mismo tiempo, si muestra lo que el ser es, ¿cómo puede cambiar con el tiempo?

En Metafísica de la expresión Nicol nos habla de la distinción entre situación cartesiana y operación cartesiana. Esta distinción la establece para mostrar que en el siglo XX se estaba volviendo a una situación similar a la que se dio con Descartes y tiene que ver con la historicidad.

La situación cartesiana "se caracteriza por un estado de crisis, en el cual se revelan como insatisfactorias no sólo algunas soluciones antecedentes, sino el fundamento mismo que sirvió para una larga serie histórica de soluciones" ${ }^{13}$. Es en este estado en el cual se dio la operación cartesiana de la duda metódica y en el cual, en el siglo XX, se dio la reducción fenomenológica de Husserl.

Este tipo de operación cartesiana se puede recoger bajo el nombre de idealismo y su característica principal es la primacía de la razón frente al ser. En este sentido la relación invierte el orden real y la cuestión del fundamento se convierte en una cuestión de derecho.

Según la operación cartesiana el ser verdadero sólo puede ser conocido desde el camino recto (método). Es en este sentido como se comprende el establecimiento de la división dualista donde la opinión es conocimiento falso y la episteme verdadero conocimiento. El conocimiento verdadero depende, en Husserl, de la evidencia apodíctica y ésta la encuentra tras poner entre paréntesis el mundo. Gracias a este "poner entre paréntesis" se puede llegar a las esencias. Gracias a la visión apodíctica llegamos a la certeza donde es imposible la duda. Este camino (método) nos muestra la evidencia desde la cual hemos luego de construir el sistema. Según Nicol esta concepción idealista tanto de la epistemología y ontología recorre toda la tradición, desde Platón y Aristóteles hasta Husserl: "La tradición perdura sin interrupciones hasta nuestros días. En el Fedón quedó establecido formalmente el contrasentido de la evidencia invisible. Dice Platón que el ser visible aquí y ahora remite a otro ser, respecto del cual el visible es inferior (phaulóteron). En cambio, nada se equipara a la evidencia (enárgueia) de lo que es en grado sumo".

Para captar las esencias, según la fenomenología trascendental, se requiere un método reductivo: "En Husserl, la captación de la esencia requiere un método reductivo. Es indudable que la esencia de la cosa no apare siempre en el

\footnotetext{
${ }^{13}$ Nicol, Eduardo, Metafísica de la expresión, México, Fondo de Cultura Económica, 1957, p. 175.
} 
momento de verla, y hay que desentrañarla. ${ }^{\prime 14}$. Pero Nicol no encuentra motivo alguno en suspender la apariencia para intuir la esencia. Es más, es en el fenómeno donde se encuentra el ser.

El supuesto de la ocultación del ser lo mantiene incluso la escuela fenomenológica contemporánea [...] Nada nos obliga a suspender la apariencia para intuir la esencia. De hecho, la suspensión es imposible. Porque la esencia pertenece al ser, y el ser está en la apariencia. Es un contrasentido poner algo del ser entre paréntesis para que su propia esencia emerja nítidamente. La razón de este contrasentido es el supuesto de la devaluación del fenómeno en que se basa la fenomenología. ${ }^{15}$

El fenómeno es manifestación directa del ser. La cuestión de la esencia no es principio sino meta de la ciencia. El ser está primero, la cuestión acerca de la esencia viene después. Por ello, el problema de la evidencia apodíctica de la fenomenología trascendental está en la subversión del ser.

En el idealismo existe una primacía de la razón frente al ser. En la fenomenología trascendental, dice Nicol, se parte del supuesto de la devaluación del fenómeno según el cual la evidencia apodíctica es verdad de razón. Por este motivo, entre otros, Nicol exige para la filosofía desligarse de la fenomenología trascendental de Husserl para partir del imperativo fenomenológico de atenernos a la realidad misma de las cosas.

La primacía de la razón frente al ser significa para Nicol ir en contra de la misma fenomenología. La evidencia no es cuestión de verdad. La evidencia primaria y universal es condición de todas las verdades y todos los errores. La evidencia apodíctica por tanto, es el fundamento de hecho, es decir, real, que da posibilidad tanto a la doxa como a la episteme. Por eso dice Nicol: "no se requiere de método ninguno para alcanzar el ser: el ser está a la vista. [...] La condición de posibilidad de una ciencia en general está ya dada en el conocimiento precientífico: es la indudable aprehensión inmediata del ser en la experiencia común y cotidiana"16. En este sentido el problema de la evidencia apodíctica cambia, ya que Husserl lo entiende de la siguiente forma: "El tener conciencia de una necesidad, o, más exactamente, el juzgar como fenómeno de conciencia en que una relación se presenta como caso especial de una univer-

\footnotetext{
${ }^{14}$ Nicol, Eduardo, Crítica de la razón simbólica, México, Fondo de Cultura Económica, 1982 p. 158.

${ }^{15}$ Nicol, Eduardo, o.c., p. 159.

${ }^{16}$ Ibíd.
} 
salidad eidética, se llama apodíctico; el juicio mismo, o la proposición, consecuencia apodíctica" ${ }^{17}$.

Es así como se nos presentan dos maneras de entender el proyecto fenomenológico. Como indica Antonio Zirión, el proyecto de la fenomenología de Husserl hace hincapié en los fenómenos de la conciencia mientras que el proyecto de la fenomenología de $\mathrm{Nicol}$ - con su afán de ir a las cosas mismas (lema de la fenomenología) - se presenta como un proyecto realista.

Con unos conceptos de fenómeno y fenomenología relativamente apartados de los sentidos etimológicos y tradicionales de estas palabras, Husserl funda su fenomenología como una ciencia peculiar, y no como un método. Fenomenología es ciencia de las vivencias de la conciencia. Es ciencia de los fenómenos porque así quiso Husserl llamarles a las vivencias, en razón de que también las vivencias podían ser "objetos intuidos", es decir, algo patente, algo que se muestra en sí mismo, como lo prescribe el sentido primitivo de la palabra "fenómeno". Esta fenomenología, esta ciencia, es algo por principio distinto de la fenomenología entendida como un método o un modo de proceder en el conocimiento científico o filosófico: el modo de proceder o el método cuya "primera regla" - según lo expresa Nicol-"impone la obligación de atenerse rigurosamente y estrictamente a lo dado". ${ }^{18}$

No obstante, hay que tener en cuenta que Husserl escribe contra el empirismo en tanto en cuanto a lo que él denomina "actitud natural" y ésta actitud es compartida, supuestamente, por la comunidad científica ${ }^{19}$. El intento de Husserl, por tanto, es "sacar" de esta presunta inocencia a los hombres de ciencia. La diferencia que nos plantea Husserl es la distinción entre mundo y realidad ${ }^{20}$. No obstante, la postura de Nicol no es que pase por alto esta actitud natural, sino que los lenguajes científicos suponen la creación de un mundo "poiesis" a través del logos, y la distinción entre mundo y realidad viene dada por la comunidad dialógica y la totalidad del ser. El ser, que es fenómeno, por tanto, no supone ningún problema, por eso no hay que poner entre paréntesis nada. La dificultad estriba en la propia comunidad de sentido, en la explicación del ser.

\footnotetext{
17 Nicol, Eduardo, Metafísica de la expresión, México, Fondo de Cultura Económica, 1957, p. 177.

${ }^{18}$ Husserl, Edmund, Ideas relativas a una fenomenología pura y una filosofía fenomenológica, traduc. J. Gaos, Madrid, Fondo de Cultura Económica, 1985, p. 26.

${ }_{19}$ Zirión, Antonio, "El sentido de la fenomenología en Nicol", en J. González y Lizbeth Sagols (eds.), El Ser y la expresión: homenaje a Eduardo Nicol, México, UNAM, 1990, p. 88.

${ }^{20}$ Cf. Heidegger, Martin, Ser y Tiempo, traduc. J. E. Rivera, Chile, Editorial Universitaria, 2005, § 7.
} 
Es por ello que para Nicol se trate de un problema de la expresión. Esto se entenderá mejor un poco más adelante.

Lo que entra en juego es la relación subversiva de la modernidad que hizo que perdiésemos el horizonte común. El carácter metodológico y la primacía de la razón frente al ser devaluaron el fenómeno. La filosofía ha de ser fenomenológica, es decir, partir de los fenómenos, esto es lo que reclama Nicol para la filosofía y es en este sentido en el cual para él es fenomenología.

El significado de la palabra "fenómeno" al cual quiere atenerse Nicol lo saca de su sentido etimológico al igual que Heidegger ${ }^{21}$. En su libro Crítica de la razón simbólica ${ }^{22}$ habla de este sentido etimológico de la palabra "fenómeno", phainómenon en griego y que procede del verbo phainesthai y significa mostrarse, manifestarse. Comparte una raíz común con el adjetivo phanerós que cualifica aquello que es claro y patente. En este sentido, la palabra latina evidens guarda una similitud con phainómenon, ya que deriva del verbo video, que significa ver y que en griego es eido, cuyo sustantivo es eidos. El fenómeno, por tanto, es lo que aparece, lo que se muestra claramente, es decir, es evidente. No obstante, ya en la filosofía antigua la relación que se establece entre la apariencia y el verdadero ser creará una nueva relación con el fenómeno. Pero de lo que no podemos dudar es de lo que nos aparece, es decir, del fenómeno ya que éste está ahí ante nosotros. De lo que podemos dudar es, en tal caso y como dice Nicol, de nuestro parecer. Lo problemático del fenómeno lo produce la filosofía al elevar aquello que no se ve a lo ontológicamente positivo y superior haciendo de lo que se ve inferior y ontológicamente negativo. En esta dinámica concibe Nicol que se ha embarcado la fenomenología trascendental de Husserl al intentar captar la esencia de la cosa a través de la reducción. Es más, el proceder fenomenológico realmente no puede poner entre paréntesis los fenómenos para encontrar su esencia sino que tiene que tenerlos siempre en cuenta. Por tanto, no es cuestión del método encontrar el ser, porque el ser es lo primero, el ser está a la vista, nos dice.

No obstante, Nicol también toma distancia respecto al planteamiento heideggeriano por considerar que éste se suma a la tradición del ocultamiento del ser. Castany i Magraner al respecto dice lo siguiente: "De todos, de quien más

\footnotetext{
${ }^{21}$ Cf. Nicol, Eduardo, Crítica de la razón simbólica, México, Fondo de Cultura Económica, 1982, § 26.

${ }^{22}$ Castany i Magraner, Bernat, "E. Nicol, un filósofo con voluntad de sistema", Enrahonar. Quaderns de filosofia, 10 (1984), p. 136.
} 
interés pone en diferenciarse es de Heidegger por ser el último intento más serio y radical de buscar una fundamentación antropológica de la Ontología, haciendo ver cómo Heidegger se encuentra vinculado a la tradición de considerar al ser "velado", como demuestra su concepción de la verdad como aletheia"23.

Esta tradición queda definida — como bien indica Herráiz Martínez recreando el planteamiento de Nicol- así:

En la tradición sustancialista esencialista del ser inmutable y unívoco, las manifestaciones de éste no son objeto de episteme, pues son múltiples y cambiantes, sino de opinión (doxa), inestable como las mismas apariencias-accidentes a las que se refiere, que por sí mismas inducen a error, son engañosas. Eso ha llevado recurrentemente a diversos intentos de afianzar el ser y el conocimiento "auténtico" frente a los accidentes y lo erróneo o inestable-inseguro. Son los distintos intentos de fundamentación ontológico-epistemológicos, siempre sobre la base de esa dualidad ontológica sujeto-objeto, del ser único escindido, del que no se encuentra que pueda ser múltiple sin separación, siempre orientando la cuestión como un intento de deshacer el "nudo" que ya Aristóteles vio en ella. ${ }^{24}$

En este sentido, la verdad para Heidegger viene ser aletheia (desocultamiento, des-velo de la cosa) ${ }^{25}$. Aún así, Ricardo Horneffer indica que el método llevado a cabo tanto por Heidegger como Nicol es el mismo en tanto que se trata de un proceder fenomenológico y éste es entendido de manera similar, pero el camino recorrido por ambos es divergente. El mayor punto de encuentro que señala es el considerar la unidad indisoluble de ontología y fenomenología ${ }^{26}$. Para Lizbeth Sagols la diferencia entre Heidegger y Nicol se encuentra en lo siguiente:

en lugar del método existenciario-individual con que Heidegger aborda la ontología del "ser ahí" en Ser y Tiempo, Nicol propone el ontológico-histórico. Lo que se buscan son las leyes de la herencia que regulan la sucesión histórica del hombre y de su pensamiento (de la búsqueda de la verdad), los ejes claves que conforman la es-

\footnotetext{
${ }^{23}$ Herraíz Martínez, Pedro-José, "E. Nicol y el problema de la expresión", Éndoxa: Series filosóficas, $17(2003)$, p. 357.

${ }^{24}$ Cf. Heidegger, Martin, Ser y Tiempo, traduc. J. E. Rivera, Chile, Editorial Universitaria, 2005, § 44.

${ }^{25}$ Cf. Horneffer, Ricardo, "De la fenómenología al misterio: Heidegger y Nicol", Theoria: Revista del Colegio de Filosofía, 3 (1996), p. 37-48.

${ }^{26}$ Sagols, Lizbeth, Prólogo, en Eduardo Nicol, Símbolo y verdad, Arturo Aguirre (eds.), México, Afinita editorial, 2007, p.10-11.
} 
tructura permanente del ser humano y el pensar en su devenir: lo que otorga mismidad y variabilidad. ${ }^{27}$

No obstante, Juliana González lo interpreta de la siguiente manera: "Nicol recuerda que el sentido más primitivo de la palabra griega que se traducirá por "verdad", la alétheia, remite, no a la cosa, no a un des-velamiento o descubrimiento de un ser que estuviera oculto o encubierto (como piensa Heidegger), sino a un des-velamiento, a un despertar del sujeto: a un estado de "alerta" o de vigilia del hombre. "Los que están despiertos, tienen un mundo común, los que duermen se vuelven hacia su mundo particular" -afirmaba asimismo Heráclito $^{\prime 28}$. Claramente Nicol considera que el Ser está a la vista y tanto el conocimiento científico como el precientífico parten de un mismo absoluto, el ser. Por tanto, para Nicol la problemática no consiste en desvelar el ser sino en cómo se expresa el $\operatorname{ser}^{29}$.

Volviendo a la tercera relación del conocimiento, la histórica, ¿cómo es posible que cambie en el tiempo la relación del pensamiento con la realidad?

La historicidad del conocimiento científico es un hecho que ha de responder la filosofía y es un hecho que se hizo más palpable con el advenimiento de la teoría de la relatividad de Einstein y la física cuántica de Heisenberg, entre otros.

En torno a la historicidad la filosofía ha mostrado diferentes caras: relativismo psicologista, escepticismo histórico, historicismo progresista (teleológico), etc. Por un lado ha habido un exceso del papel de la persona en relación con la verdad y/o de la situación histórica y por otro lado un exceso de la racionalidad de la historia según la cual existiría un progreso hacia la verdad (como si el espíritu fuera desenvolviéndose hacia la verdad y la verdad fuese una de las metas de la historia) donde sólo los errores son históricos.

Nicol, al respecto, nos dice que la verdad y el error no pueden tener explicaciones diferentes ya que ambas parten del ser. En este sentido las posturas idealistas resultan una posición bastante cómoda ya que al establecer la verdad

\footnotetext{
27 González, Juliana, "Logos y ethos en la filosofía de Eduardo Nicol" Theoria: Revista del Colegio de Filosofía, 3 (1996) p.29.

${ }^{28}$ Para más información acerca de las diferencias y semejanzas entre Heidegger y Nicol puede consultarse: Luis Santos, María, "Nicol y Heidegger, indicaciones sobre una divergencia fundamental" Eduardo Nicol: la filosofía como razón simbólica, Anthropos, Extra 3, 119-127

${ }_{29} \mathrm{Nicol}$, Eduardo, La reforma de la filosofía, México, Fondo de Cultura Económica, 1980, p. 40.
} 
desde el método nos permiten distinguir con bastante claridad entre la verdad y el error. Pero esta facilidad se ve quebrantada con la historicidad.

Por tanto, el problema con el que ha de enfrentarse la filosofía es con la explicación del devenir histórico. El problema del conocimiento requiere que se explique el orden del cambio. Esta tercera relación del conocimiento, es decir, la relación histórica, estaría integrada por una doble estructura que Nicol llama: la estructura vertical y la estructura horizontal. Esta tercera relación del conocimiento es exigencia que deriva de la ontología del conocimiento, por tanto, comprende las dos relaciones del conocimiento ya mencionadas, la epistemológica y la lógica. La doble estructura del proceso histórico supone que de la relatividad histórica no se infiere necesariamente una conclusión relativista. "La aparición de sistemas se produce de acuerdo con una doble estructura vertical y horizontal. [...] La situación constituye la estructura vertical en que se inscribe la obra; pero ésta se inscribe además en el proceso general de la filosofía. La estructura horizontal confirma la unidad de la filosofía en la continuidad de sus operaciones" ${ }^{\prime 30}$.

La estructura vertical viene a ser la situación histórica, mientras que la estructura horizontal es la continuidad dialéctica del proceso histórico.

Los historicismos o perspectivismos relativistas son aquellas filosofías que sólo atienden a la situación histórica, es decir, a la estructura vertical. Pero cada situación histórica no es una parcela incomunicada, no se trata de un estanco, sino que son procesos en continua transformación. La negación de la continuidad orgánica de la historia que realizan los historicismos suponen, en su máxima radical, que cada situación histórica surja de la nada. Es el advertencia de esos "principios internos de secuencia" esos "motores" del cambio lo que hacen que nos demos cuenta que la historia tiene una "razón" y esa "razón" es la que hace no caer en esos relativismos subjetivistas. En este sentido, la historia es mutación estructural y dialéctica.

Crisis significa primitivamente separación y selección; sin embargo, el método correcto de la crítica histórica debe conducir a un resultado opuesto. La crítica de la razón es una crítica histórica. No es selectiva, sino omnicomprensiva; no abstrae o separa cada sistema particular, sino que lo integra en el sistema procesal. Una tesis, que en griego quiere decir una posición, es siempre una respuesta a otra posi-

30 Ibíd. 
ción anterior. La contra-posición es una com-posición que mantiene el engranaje histórico de las posiciones singulares. ${ }^{31}$

Nicol mantiene que es en estas tres relaciones del conocimiento donde se ha manifestado la crisis ya que la relación histórica es la que complica la explicación de la verdad por dos motivos: atendiendo a la estructura vertical la verdad es expresión de la situación histórica; si atendemos a la estructura horizontal parece que la verdad depende más del pasado histórico que de la adecuación a las cosas mismas. Ante esta tesitura Nicol advierte que la solvencia de tal problemática tiene que ver con la cuarta relación del conocimiento que él denomina "relación dialógica".

Por tal razón, la ley del proceso no debe formularse con criterio polémico: la estructura horizontal no es una dialéctica externa, como una secuencia de tesis que se excluyen unas a otras sin dejar sedimento, que han de quedar canceladas sólo porque son productos de situaciones distintas. De este modo, en cada momento de su actualidad, la filosofía rompería su línea genealógica y anularía todo su pasado. En verdad, su desarrollo sería una mera sucesión de interrupciones. ${ }^{32}$

Esta cuarta relación del conocimiento muestra cómo se ha producido un malentendido con la primera relación del conocimiento, que es la relación epistemológica, ya que esta primera relación sólo atiende al sujeto aislado cuando, en realidad, todo conocimiento supone un diálogo como mínimo entre dos sujetos estableciéndose, así, una relación triangular sujeto-objeto-sujeto. La clave de todo ello es la expresión.

La característica de la cuarta relación del conocimiento de la que habla $\mathrm{Ni}$ col es el diálogo, de ahí que él la denomine relación dialógica. Nicol nos advierte que cuando pensamos en la verdad solemos pensar en la relación epistemológica del sujeto puro con el objeto puro según la cual el logos teorético formula juicios universales. Pero la abstracción del sujeto aislado frente al objeto es un artificio que además nunca puede implicar conocimiento. En palabras de Nicol:

\footnotetext{
${ }^{31}$ Ibíd., p. 41.

32 Nicol, Eduardo, La vocación humana, México, Fondo de Cultura Económica, 1953, p. 303.
} 
Si el conocimiento fuera mi conocimiento, y la verdad mi verdad, no habría de hecho ni verdad ni conocimiento. Pues jamás otro sujeto pudiera tener acceso a mi conocimiento y compartirlo, compartiendo por ello la realidad conocida [...] E inversamente, si esta realidad no fuese común a dos o múltiples sujetos, el logos que emplease cada uno para manifestar su conocimiento sería absolutamente ininteligible para todos los demás. El hecho de la verdad es el hecho primario y patente del entendimiento: ¿Nos entendemos? Luego hay verdad. ${ }^{33}$

Para entender fenomenológicamente el conocimiento hemos de acercarnos a su sentido elemental y éste sentido es el entendimiento, es decir, la comunicación. Todo logos es dia-logo. La concepción del logos como dia-logo supone retomar el sentido etimológico del vocablo en sus dos acepciones: razón y palabra. Es a través del logos como se consigue el entendimiento, es decir, a través de la palabra. El logos, es la unión entre dos sujetos que hablan de algo común. En palabras de Nicol: "la condición de posibilidad de un entendimiento es la existencia de una realidad común, hecha patente por el logos" ${ }^{\prime 34}$. Esta relación dia-lógica del logos supone una relación tripolar de sujeto-objeto-sujeto. ¿Por qué es tan importante esta relación dialógica del logos? Porque nos da cuenta de la naturaleza del logos, el logos no es puro sino que es simbólico. "El diálogo concluye la fase primaria del conocimiento, constituye a la cosa propiamente en objeto, mediante su definitiva identificación, y es la base apodíctica que permite considerar a los entes como tales, o sea como realidades, antes de que surja o se resuelva el problema de una fundamentación del conocimiento como episteme" ${ }^{\prime 37}$.

El logos como palabra, que es expresión, implica un significado. Este significado surge de la comunicación, del dia-logo entre una comunidad de sujetos que versan sobre algo común que es el ser. El ser que es fenómeno -como señalamos al principio- se manifiesta a través de la palabra, a través del logos y en este sentido el ser es común y el logos supone comunidad. La comunidad de sentido siempre es co-sentido porque es consenso, se consiente, se identifica con una misma realidad.

Cuando la expresión es un simple gesto que señala: esto ahí, es manifestación directa del ser, es expresión apofántica. Pero incluso en esta función básica de la expresión requiere de un otro al cual se le presenta eso que se señala. La

\footnotetext{
${ }^{33}$ Nicol, Eduardo, La vocación humana, México, Fondo de Cultura Económica, 1953, p. 303.

34 Nicol, Eduardo, Metafísica de la expresión, México, Fondo de Cultura Económica, 1957, p. 191.
} 
palabra también es muestra del ser, es un acto poiético del hombre que trata a través del logos presentar el ser al otro. En este sentido, el logos que es símbolo supone un acto poiético. Nicol, en un artículo de Diánoia llamado "Pluralidad y verdad" nos recuerda que el logos es apóphansis, es decir, declaración o revelación. En este hecho declarativo, mostrativo del ser, se produce un acto poiético por el hecho de ser simbólico porque aunque el logos (razón y palabra) presente el ser, la palabra misma que lo presenta es una creación del hombre. No obstante, "cuanto más unívoco se hace el símbolo verbal, y más riguroso es el sistema formal de los símbolos, tanto más se alejan éstos de la aprehensión inmediata de la realidad" 35 . La consecuencia es clara: "Si no fuese más que una presentación, la ciencia no sería histórica; si fuese meramente una creación histórica, no podría ser un sistema de verdades"36.

Lo que nos viene a decir Nicol es que si queremos entender el conocimiento, así como la verdad, hay que acercarnos a ello desde una mirada fenomenológica. Ahora es cuando podemos comprender el sentido de la fenomenología dialéctica de Nicol. Lo que sucede con ciertas filosofías es que no han tenido cuidado en su mirar y en lugar de realizar una descripción ontológica del mismo, lo que han llevado a cabo es una acción regulativa. Esta acusación se vuelve expresa hacia Descartes y Husserl cuando Nicol dice de ambos que en lugar de estudiar cómo conoce el hombre y cómo funciona su ser en tanto que cognoscente, han procurado establecer el cómo debe proceder el hombre para que su conocimiento sea verdadero y todo ello con una idea preconcebida de la verdad. Esta operación es realizada por la dualidad ontológica ( $y$ en consecuencia epistemológica) del ser verdadero y el ser aparente.

Por tanto, ambas filosofías en lugar de ser descripciones ontológicas devienen en prescripciones regulativas. En este sentido, necesitan un camino (método) que conduzca a la verdad apodíctica. La denuncia primera a esta concepción del conocimiento que realiza Nicol es ese "darle la vuelta" a la apodicticidad.

Lo que señala Nicol es que lo realmente apodíctico es el fenómeno porque es lo que se muestra, es patente, y el ser sólo puede ser entendido como lo presente. En este sentido el ser es par-ousía. Sin embargo, esta patencia del

\footnotetext{
${ }^{35}$ Ibíd., p. 304.

${ }^{36}$ Nicol, Eduardo, "Pluralidad y verdad. Unidad y comunidad del ser", Diánoia, vol. 24, na24, (1978), p. 20.
} 
ser no es suficiente si de lo que queremos hablar es del conocimiento y de la verdad. El ser sólo se nos presenta cuando lo presentamos, es decir, cuando lo expresamos. En este sentido el logos es presentación del ser, pero toda presentación siempre es hacia alguien, y he ahí la importancia del otro. El conocimiento es dia-logo por varios motivos: primero y básico porque todo conocimiento sólo es conocimiento si es compartido; segundo porque para compartirlo hay que comunicarlo; tercero se necesita una comunidad de sentido para ser entendido y esto es el logos: comunidad. El logos se manifiesta como sistema simbólico cuya función es el entendimiento.

Las denuncias por parte de Nicol son varias, la más reiterativa es el solipsismo. Según indica Enrique Hülsz Piccone "Se trata, desde luego, de una categoría rigurosamente ontológica [la expresión], con la que Nicol piensa el ser del hombre, y a través de la cual se resuelve la otra gran aporía de la tradición metafísica (la primera, [...] es la "ocultación del ser"): [la segunda] el solipsis$\mathrm{mo}^{\prime 37}$. Y esta concepción solipsista del conocimiento procede de entender la episteme sólo en dos de sus cuatro relaciones, es decir, en su relación lógica y epistemológica las cuales se plantean siempre desde el individuo aislado. Por eso Nicol dice: "el solipsismo es una consecuencia teórica inevitable de ese planteamiento que concibe el conocimiento como una relación constituida solamente por los dos términos que son un objeto y un sujeto que está, a solas, frente a él" ${ }^{\prime 38}$. Es de ahí de donde podemos nosotros pensar que, quizás, proceda el sentido regulativo del conocimiento en las filosofías idealistas en ese intento de superación del fenómeno de la historicidad. Pero cuando la historicidad se acepta - ya que es fenómeno-, el problema no disminuye sino que cabe explicarlo. Y la mejor forma que encuentra Nicol de hacerlo es a través de una fenomenología que es dialéctica por el carácter constitutivo del logos, que es dia-logo.

En este sentido, cabe pensar que el mundo de la vida (Lebenswelt) de Husserl intenta paliar las acusaciones de solipsismo que traía su fenomenología trascendental. No obstante, como señala Javier San Martín ${ }^{39}$, puede que la introducción de dicho concepto procediese de las acusaciones de intelectualismo

\footnotetext{
${ }^{37}$ Hülz Piccone, Enrique, "Metafísica y humanismo en la filosofía de Eduardo Nicol", Eduardo Nicol: la filosofía como razón simbólica, Anthropos, Extra 3, p. 79.

38 Nicol, Eduardo, Metafísica de la expresión, México, Fondo de Cultura Económica, 1957, p. 263.

39 San Martín, Javier, La fenomenología de Husserl como utopía de la razón, Barcelona, Editorial Anthropos, 1987, p.29.
} 
a las cuales fueron referidas su fenomenología. Aún así, dicho concepto es visto por J. San Martín como una explanación del mundo de la experiencia (Erfahrungswelt). Tanto el mundo de la experiencia como el mundo de la vida pueden considerarse desde la perspectiva de Nicol como esos horizontes de sentido en los cuales el hombre desarrolla sus actividades, incluida la epistemológica. En este sentido la Lebenswelt podría considerarse como ese horizonte simbólico al que alude Nicol. Si bien, ambos proyectos se distinguen, y puede ser más acertado comprender la fenomenología nicoliana como un punto intermedio entre la fenomenología trascendental de Husserl y la fenomenología hermenéutica de la facticidad de Heidegger ya que, aunque ambos tienen como seña común la relación con el mundo, el trato con el mismo es distinto. Como indica J.M.G. Gómez-Heras ${ }^{40}$, mientras el acercamiento por parte de Husserl es desde el saber experimentado por el vivir de la conciencia, en Heidegger es desde el existir en su ser-en-el-mundo. Por este motivo, podemos admitir que en Nicol la problemática del saber confluye con la facticidad del existir $y$, en este sentido, puede comprenderse la fenomenología nicoliana como un punto intermedio entre la fenomenología trascendental de Husserl y la fenomenología hermenéutica de la facticidad de Heidegger.

Al respecto, Antonio Zirión comenta lo siguiente:

Sería demasiado fácil decir, desde la ortodoxia husserliana, que Nicol no ha podido abandonar la "actitud natural"; que sigue inmerso en la ingenuidad de dar por supuesta la existencia del universo; que su filosofía primera, su ciencia de la ciencia, parte indebidamente de los mismos presupuestos y comparte los mismo prejuicios que la ciencia natural; que no ha entendido el sentido genuino de la reducción trascendental y en consecuencia no ha podido adoptar el punto de vista y la actitud genuinamente filosóficos. ${ }^{41}$

Y continúa comentando Zirión que aún así, la problemática señalada por Nicol del solipsismo que se encuentra en el idealismo trascendental que presenta la fenomenología de Husserl no cesaría y, en ese sentido, lo ve como un "callejón sin salida".

\footnotetext{
${ }^{40}$ Cf. Gómez-Heras, José Ma Ga, "Comprender el mundo. La valencia hermenéutica del binomio «Lebenswelt» (Husserl) e «In-der-Welt-Sein» (Heidegger)", Anales del Seminario de Metafísica, Núm. Extra. Homenaje a S. Rábade (1992), 285-319.

${ }^{41}$ Zirión, Anotnio, El sentido de la fenomenología en Nicol, en J. González y Lizbeth Saglos (eds.), El Ser y la expresión: homenaje a Eduardo Nicol, México, UNAM, 1990, p. 92.
} 
Quizás sea el siguiente texto el que mejor desvele la postura nicoliana:

La verdad no es pura relación del sujeto con el objeto, ya se conciba como adecuación, a la manera tradicional, o como revelación. La representación simbólica es la única forma lógica posible de adecuación entre los dos términos heterogéneos que son el intellectus y la res. Y el diálogo es la forma esencial de la apóphansis o revelación del ser por la palabra [...] La verdad es, por tanto, una forma de comunidad, lógica y dialógica, por la cual se determina la forma de ser en común del hombre. [...] hay que advertir que el ser revelado en él y por él primariamente es el ser del hombre mismo, ontológicamente vinculado al otro por su esencial condición de parlante. Lo que debe entonces aclarar la ontología de la verdad es la manera como se implican en la palabra la creación expresiva y la representación adecuada, a la cual llamamos conocimiento. Ambas, a su vez, implican ontológicamente al "otro". Mientras estas implicaciones no queden al descubierto, la cuestión del "criterio" de la verdad resultará un problema insoluble. ${ }^{42}$

En este sentido la fenomenología de Nicol es ontología y la ontología es fenomenología cuando vemos la inevitable inclusión del tema del ser con el tema del método. Esta aprehensión del ser que es parousía y por ello apóphansis, sólo se realiza a través del logos que es dia-logo. Es decir, sin el otro no hay conocimiento porque el conocimiento es comunidad. A través de la expresión como símbolo - que es poiesis- dialogado se presenta el ser y en este sentido la fenomenología dialéctica no sólo es método y conocimiento sino que es metafísica, metafísica de la expresión, es decir, metafísica de la razón simbólica y dialógica.

BibliografíA

CAStAny i Magraner, Bernat, "E. Nicol, un filósofo con voluntad de sistema", Enrahonar. Quaderns de filosofia, 10 (1984), p. 135-142.

Gómez-Heras, José Maga, "Comprender el mundo. La valencia hermenéutica del binomio "Lebenswelt" (Husserl) e "In-der-Welt-Sein" (Heidegger)", Anales del Seminario de Metafísica, Núm. Extra. Homenaje a S. Rábade (1992), 285-319.

GonzálEz, Juliana, "Logos y ethos en la filosofía de Eduardo Nicol" Theoria: Revista del Colegio de Filosofía, 3 (1996) p.25-35.

42 Nicol, Eduardo, La vocación humana, México, Fondo de Cultura Económica, 1953, p. 344. 
- "El ser que habla del ser (Metafísica y Ética en Eduardo Nicol)". Eduardo Nicol. La filosofía como razón simbólica, Revista Anthropos, Extra 3 (1998), p. 56-65.

Heidegger, Martin, Ser y Tiempo, traduc. J. E. Rivera, Chile, Editorial Universitaria, 2005.

Herraíz Martínez, Pedro-José, "E. Nicol y el problema de la expresión", Éndoxa: Series filosóficas, 17(2003), p. 355-377.

HORNEFFER, Ricardo, "De la fenómenología al misterio: Heidegger y Nicol", Theoria: Revista del Colegio de Filosofía, 3 (1996), p. 37-48.

- "Eduardo Nicol (1907-1990)" en E. Dussel; E. Mendieta; C. Bohórquerz (editores), EI pensamiento filosófico latinoamericano, del Caribe y "latino" (1300-2000): historia, corrientes, temas y filósofos, México, Siglo XXI, 2009, 837-838.

Hülz Piccone, Enrique, "Metafísica y humanismo en la filosofía de Eduardo Nicol", Eduardo Nicol: la filosofía como razón simbólica, Anthropos, Extra 3, p. 76-80.

HUSSERL, Edmund, Ideas relativas a una fenomenología pura y una filosofía fenomenológica, traduc. J. Gaos, Madrid, Fondo de Cultura Económica, 1985.

LuIS SANTOS, María, "Nicol y Heidegger, indicaciones sobre una divergencia fundamental" Eduardo Nicol: la filosofía como razón simbólica, Anthropos, Extra 3, 119-127.

Nicol, Eduardo, La vocación humana, México, Fondo de Cultura Económica, 1953.

- Metafísica de la expresión, México, Fondo de Cultura Económica, 1957.

- Los principios de la ciencia, México, Fondo de Cultura Económica, 1974.

- "Pluralidad y verdad. Unidad y comunidad del ser", Diánoia, vol. 24, na24 (1978), 1825.

- La reforma de la filosofía, México, Fondo de Cultura Económica, 1980.

- Crítica de la razón simbólica, México, Fondo de Cultura Económica, 1982.

R. DE Nicol, Alicia, "Eduardo Nicol. La vocación cumplida". Eduardo Nicol. La filosofía como razón simbólica, Revista Anthropos, EX03 (1998), 46-55.

SAgols, Lizbeth, "Prólogo" en Eduardo Nicol, Símbolo y verdad, Arturo Aguirre (eds.), México, Afinita editorial, 2007.

SAn MARTín, Javier, La fenomenología de Husserl como utopía de la razón, Barcelona, Editorial Anthropos, 1987, p. 29.

Zirión, Antonio, "El sentido de la fenomenología en Nicol" en J. González y Lizbeth Sagols (eds.), El Ser y la expresión: homenaje a Eduardo Nicol, México, UNAM, 1990. 